\title{
Suspended sediment transport map for disaster mitigation in the upper course of Jangkok River
}

\author{
Yusron Saadi ${ }^{1,2 *}$ IB Giri Putra ${ }^{2}$, and Agus Suroso ${ }^{2}$ \\ ${ }^{1}$ Center for Disaster Risk Management, University of Mataram, Indonesia \\ ${ }^{2}$ Department of Civil Engineering, University of Mataram, Indonesia
}

\begin{abstract}
Jangkok River, a very important river for irrigation purposes in Lombok Island Indonesia is experiencing a rapid change in the land use of its watershed. The conversion of trees into seasonal crops in the watershed causes a decrease in the carrying capacity of the watershed and reduces its ability to prevent soil erosion. Environmental damages such as erosion and sedimentation along the river are becoming increasingly difficult to control. This paper proposed an idea to identify river conditions based on suspended sediment concentration. A series of field measurements of suspended sediment concentrations and river flow discharges were carried out to obtain the relationship between these two parameters. A resulting watershed map contains information on the rate of suspended sediment transport in the form of a suspended sediment-flow discharge rating curve is designed as a sediment conservation health indicator of the watershed. The map allows the authority to observe the condition of each river order in the upper course of the Jangkok River since the nearby tributaries are most likely to have their pattern of suspended sediment transport rate. The finding from this preliminary study can facilitate the drafting and implementation of the right policy in watershed conservation management planning which leads to preventive action and better preparedness in disaster mitigation.
\end{abstract}

\section{Introduction}

The problem of river management is growing and the balance of nature, especially in river catchment areas is increasingly in danger due to the development of human activities. River management includes river conservation, river development, and control of water destructive power to the environment [1]. Law No. 17 of 2019 concerning Water Resources states that the destructive power of water is the power of water that is detrimental to life [2]. The destructive power of water can be in the form of floods, erosion and sedimentation, and landslides.

In the context of controlling the destructive power of water, it is also necessary to make efforts in the form of non-physical measures other than physical activities. Non-physical measures are in the form of a conservation project to maintain the existence and sustainability of the natural condition and function of the river. Its flow should always be available sufficiently both in quantity and quality to meet the needs of humans and other living organisms both in present and in the future. One thing very urgently needs to be carried out is to identify river conditions and to diagnose the problems faced by the river and its watershed. Inspection of a watershed environment is analogous to a human health checkup [3]. The so-called watershed health indicators are a set of indicators which easily and directly measured. These indicators can express the health condition in an observed watershed.

Existing health indicators mainly focused on water quality and ecological conditions. In recent years health indicators develop and accommodated parameters such as runoff ratio, denudation depth, vegetation cover ratio, turbidity, and sediment concentration [4]. The purpose of the research is to create a watershed map that contains information on one of those indicators, i.e. sediment concentration in the upper course of Jangkok River in Lombok Island. The watershed was selected based on being a very important river with the main river contributing significantly to the island development in terms of meeting irrigation needs.

Suspended sediment concentration can be used to express the state of the watershed in the upper course of the Jangkok River representing the rate of sediment transport for each river segment from tributaries to the main river. This map is expected to be used as a guide to finding out which river segments need attention according to the level or rate of suspended sediment transport. The indicator will be transformed into an equation that describes the relationship between suspended sediment concentration and river flow discharge. The suspended

*Corresponding author: y.saadi@unram.ac.id 
sediment-flow discharge rating curve allows identification and examination of the state of the subwatershed that are sensitive to erosion and the subwatershed that are relatively stable.

The production of the map will be used by the authority as a basis to determine a watershed conservation plan with treatment priorities that can be arranged by putting rivers with a high suspended sediment concentration as the initial treatment target. This is particularly important in the way to anticipate governmental limited conservation budget so that the comprehensive watershed conservation arrangement can be carried out in stages for each fiscal year.

\section{Soil erosion and sediment continuity concept}

Conversion of land use in the catchment area from hard crops into seasonal crops such as food crops and vegetables is immensely popular amongst people living in the nearby forest in the upper course of the Jangkok River. They did not realize the negative impact of these activities on the environment on a larger scale. The government also fails to properly address these issues as people always forward the economic reasons behind their activities. Government intervention will be considered as halting an increase in the income of people living in the watershed. This has been proven to cause uncontrolled conservation of watersheds which results in the increase of sedimentation transportation rates due to increased soil erosion. This type of erosion is considered one of the most serious environmental problems that cause soil nutrient loss and land degradation $[5,6]$.

A lot of research has been devoted to quantifying the effects of vegetation cover on soil erosion, e.g. Mahmoudzadeh et al. [7], Sharma [8], Han et al. [9], and Guo et al. [10] amongst others. It has been proven that vegetation can improve soil physical and chemical properties and erosion resistance [10]. Soil erosion generally flows toward river valleys and the transportation of sediment downstream leads to siltation which can reduce the cross-sectional capacity of the river. Subsequent floods harm the community and damage existing infrastructures. High sedimentation rates can also cause silting in the reservoir and reduce the effective lifetime of such a structure.

In recent years all parties gradually understood that uncontrolled land-use conversion activities not only had a local impact but also often affected the upper course and lower course of the watershed [4], threatening regional even global ecological security patterns and human development $[11,12]$. Change in the form of land use may intensify soil erosion along the slope direction and contribute to an increase in river sediment transportation.

Measurement of river sediment is often considered something difficult to carry out. This activity is also receiving less attention from the authorities and is considered to have low urgency even though the magnitude and intensity of river sediment transport can be used as one of the parameters to determine the degradation level of a watershed [13]. Another limitation is that many assume the sediment transport behavior of the nearby rivers is identical and is considered to have similar patterns even though different conservation practices in the adjacent rivers and subwatershed are applied [14]. Lack of attention and the low level of urgency is the main reason that sediment measurements are usually limited in number. Each river, including its sub-watersheds, can have different characteristics in terms of sediment transport rate even though they are geographically located nearby [14]. Research conducted on three main rivers flowing into a reservoir by Saadi [15] showed that those rivers have a suspended sediment transport rate of two to fivefold different even though they are closely located. The finding indicates that the measurement of the sediment transport rate of each river in a watershed is very relevant and useful so that the respective sediment transport rates can be obtained.

The amount of sediment material transported, eroded, and deposited in rivers, especially alluvial rivers, is a function of sediment supply and sediment transport capacity by rivers. Sediment supply is obtained from soil loss within the watershed, riverbanks erosion, and river bed degradation. Sediment carrying capacity is a function of sediment size, flow rate, and geometric and hydraulic properties of the river. The equilibrium state is achieved when the carrying capacity, i.e. sediment transported by the flow is equal to the supply of sediment. In reality, it is difficult to achieve this condition, partly because the river bed stability can vary significantly even during floods of the same magnitude [16]. This is supported by the nature of the river bed which is formed from sediment particles with non-uniform grain sizes.

The concept of sediment continuity in a river reach for a certain period is expressed by the amount of sediment flowing into and deducted by the amount of sediment flowing out at the downstream end of the reach equal to the amount of sediment stored within the reach. Sediment entering the river reach can be in the form of sediment flow through the cross-section at the upstream part coupled with sediment input from both sides of the river which is the result of soil erosion from the watershed. The sediment carrying capacity by the flow determines the rate of sediment.

The stability of the river bed is strongly influenced by the nature of the flow, i.e. the flow hydrograph pattern. Continuous material transportation usually occurs in the early stages of the flood hydrograph because the riverbed material has not been well consolidated. A longer flood hydrograph increases the stability of the riverbed to a certain level due to the armoring process that takes place on the riverbed. When subsequent flood hydrograph passes the riverbed, sediment transport rate does not necessarily increase linearly even though the flood hydrograph is larger than the previous one [16].

\section{Methodology}

\subsection{Location of the study}

Water assessment and suspended sediment sampling was carried out in the upper course of Jangkok River in 
Lombok Island (Fig. 1). Six measurement points were selected based on the field condition. Tembiras River was divided into upstream (T1) and downstream (T2) locations, while Jangkok River was divided into Jangkok upstream (J1) and Jangkok downstream (J2). A point each was selected in smaller tributaries called Bentoyang River (B) and Pemoto River (P). The number of samples for each location was 24 samples or 148 samples in total.

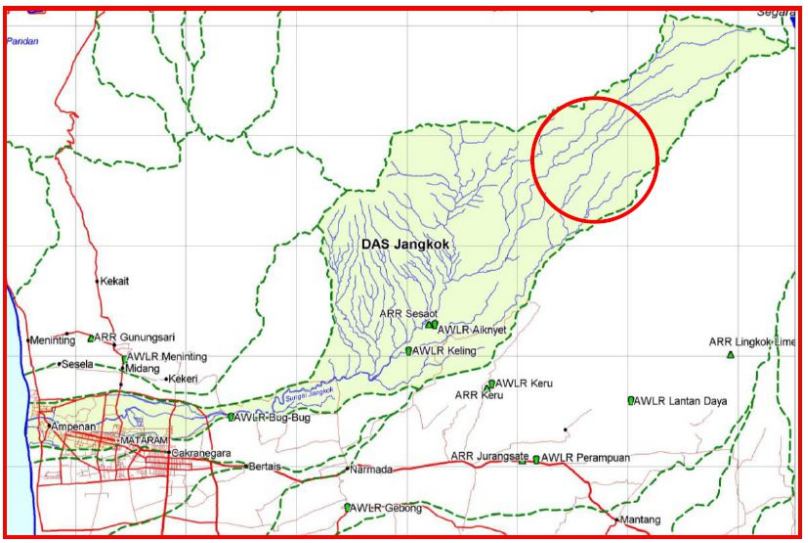

Fig. 1. Measurement location of flow discharge and suspended sediment

\subsection{Flow discharge measurement}

Measurement of river flow discharges was carried out at the same location with the measurement of suspended sediment to obtain an accurate relationship between suspended sediment concentration and river flow discharge. The standard procedure is to plot the daily flow discharge hydrograph and the daily sediment concentration graph. Measurement of flow discharge begins with measuring the cross-sectional area of the river. At the same point, the flow velocity measurement was carried out so that the river flow discharge can be obtained.

Flow discharge at a predetermined location was observed. The flow velocity was measured by flow meter wading set as shown in Fig. 2, whereas the water assessment was carried out between tributaries to the main river. To obtain representative data on flow velocity measurements and water assessments, measurements were made during rainy and dry seasons.

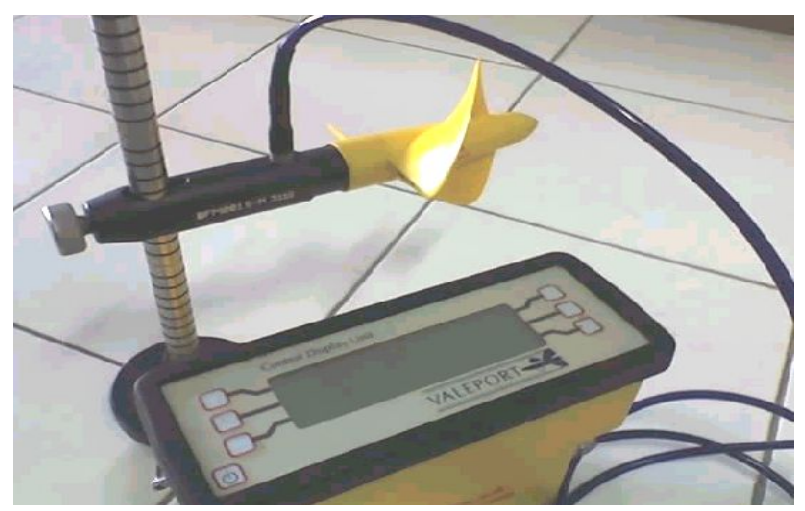

Fig. 2. Flowmeter of Valeport Model 001

\subsection{Suspended sediment concentration}

The measurement of suspended sediment concentration in the river is generally an adoption of a conventional method, namely the depth integration method [17]. This method measures the suspended sediment at three different water depths, i.e. $0.2 \mathrm{~h}, 0.6 \mathrm{~h}$, and $0.8 \mathrm{~h}$ from the water surface ( $h$ is the water depth). According to Engineer Manual 1110-2-4000, the sediment concentration in the unmeasured zone is usually estimated to be from $5-15 \%$ of the measured concentration [18]. Suspended sediment sampling was carried out after the discharge measurement was completed.

The measurement of suspended sediment concentration was carried out at the same location as the flow velocity and water assessment. Measurements were made using a suspended sediment sampler and a cylinder water sampler as shown in Fig. 3 and Fig. 4. In terms of proportional dimensions, a cylindrical measuring instrument can provide more accurate measurement results with a trapping efficiency of $0.8-1.2$ for a moderate velocity [19]. Filtering and weighing samples were carried out to separate sediment contained in the water sample. Measurements of flow discharge and suspended sediment concentration were carried out as much as possible at various locations so that the existing samples represented the actual condition of the river.

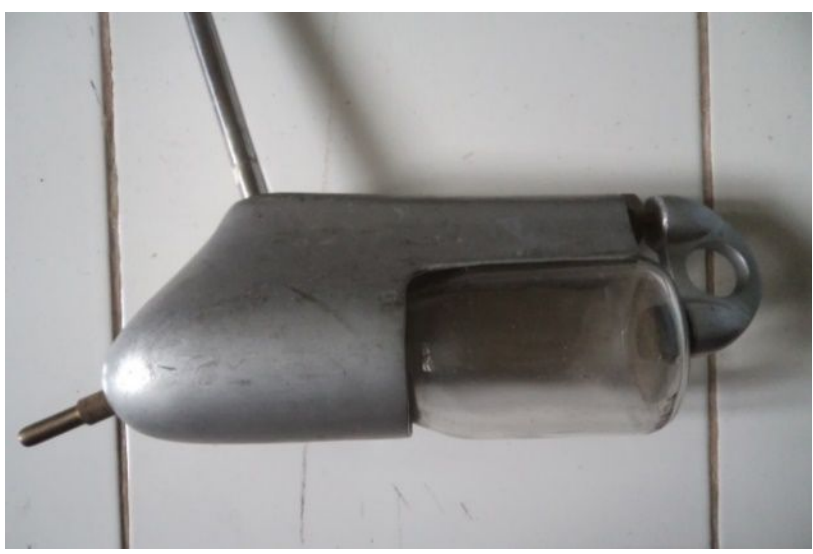

Fig. 3. Suspended sediment sampler of US DH 48 type

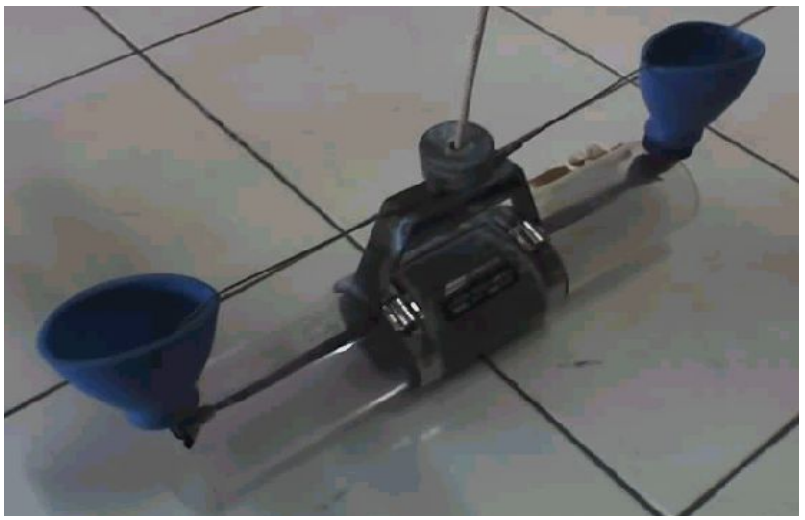

Fig. 4. Cylinder Water Sampler of LaMOTTE Model JT-1

In addition to field measurements, secondary data in the form of hydrological, climatological, land use, and other technical data were prepared. Watershed-related 
maps and additional information were also collected accordingly.

\subsection{Suspended sediment-flow discharge rating curve}

Processing data series that will be transformed into a mathematical equation is carried out by numerical analysis. In general, the most common data processing techniques require an understanding of the regression method whose analysis results are presented in the form of a smoothed curve (fitting curve). One of the methods is the least square method which minimizes the sum of the squares of the deviations formed by the resulting line [20]. Before the least-squares method is employed, discharge data and sediment concentration are written in the form of a logarithmic equation. In the least-squares method, the error is defined as the deviation or difference between the true value and the measured value.

The relationship between suspended sediment concentration and flow discharge is expressed by a logarithmic graph which can be mathematically expressed by an equation in the following form

$$
Q_{s}=a Q_{w}{ }^{b}
$$

where :

$$
\begin{aligned}
Q_{s} & =\text { suspended sediment rate }(\mathrm{gr} / \mathrm{lt}) \\
Q_{w} & =\text { flow discharge }\left(\mathrm{m}^{3} / \mathrm{det}\right) \\
a & =\text { coefficient } \\
b & =\text { exponent }
\end{aligned}
$$

Based on the consideration that flow fluctuations from year to year are varied, the relationship between the measured flow discharge and the suspended sediment concentration originated from the sample is a correlation between the two factors at the time of measurement [15]. The soil erosion level may not the same for every rainfall because it depends on rainfall intensity, soil conditions, and plant growth. Certain parts of a river's reach may be more sensitive to erosion than others so that a larger sediment flow can be expected when rainfall is concentrated in the area. This shows that suspended sediment transport rate and the river flow discharge are not always directly correlated. However, the suspended sediment-flow discharge rating curve is a very useful tool for estimating suspended sediment transport rate.

\subsection{Numerical analysis and suspended sediment samples test}

Numerical analysis is carried out to obtain the flow discharge-suspended sediment rating curve. The analysis is conducted in two stages. The first stage is the collection of flow discharge data and suspended sediment concentration. The second stage is data processing using the least square method.

The least-squares method is employed by presenting an equation containing the relationship between suspended sediment concentration and river flow discharge (Equation 1) in the form of a logarithmic equation as follows;

$$
\log Q_{s}=\log a+b \log Q_{w}
$$

if $Q_{s}{ }^{\prime}=\log Q_{s}, \quad Q_{w}{ }^{\prime}=\log Q_{w}$ and $a^{\prime}=\log a$,

$$
Q_{s}{ }^{\prime}=a^{\prime}+b Q_{w}{ }^{\prime}
$$

Therefore, the residual equation is

$$
\begin{aligned}
& R=\sum_{i=1}^{n} R_{i}^{2}=\sum_{i=1}^{n}\left(a^{\prime}+b Q_{w i}^{\prime}-Q_{s i}^{\prime}\right)^{2} \\
& \frac{\gamma R}{\gamma a^{\prime}}=2 \sum_{i=1}^{n}\left(a^{\prime}+b Q_{w i}^{\prime}-Q_{s i}^{\prime}\right)=0 \\
& \frac{\gamma R}{\gamma b}=2 \sum_{i=1}^{n}\left(a^{\prime}+b Q_{w i}^{\prime}-Q_{s i}^{\prime}\right) Q_{w i}^{\prime}=0
\end{aligned}
$$

Sediment samples taken from the field are observed at both Geotechnical Laboratory and Hydraulics and Coastal Laboratory, Faculty of Engineering, University of Mataram. The types of tests are volumetric/ gravimetric tests and sieving analysis. Parameters resulting from these tests are specific gravity, grain size analysis (gravel, sand, silt, and clay), and the soil volume weight of wet and dry conditions.

\section{Results and discussion}

\subsection{Suspended sediment samples}

Suspended sediment measurements were carefully carried out at a location with minimum disturbance and no backwater influence (Fig. 5). This was intended to allow the suspended sediment to enter the sampler in a very smooth fashion. Following the measurement, trapped sediment was removed and stored in a bottle or a container (Fig. 6). Twenty-four samples for each location were labeled for further analysis in the laboratory.

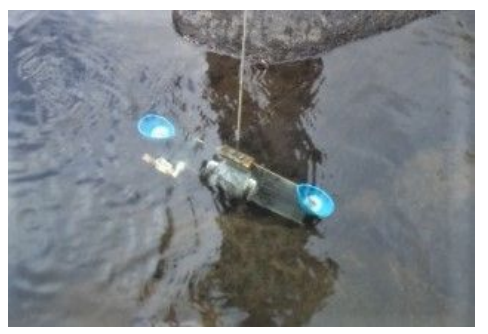

Fig. 5. Sediment sampling measurement using Cylinder Water Sampler (LaMOTTE Model JT-1)

Subsequent laboratory analyses such as weighing wáter and sediment followed by drying simple in the oven were conducted. After the dry weight of samples was recorded, the relationship between flow discharge and suspended sediment concentration can be obtained. The 
problem faced during this process was the measurement results with very little suspended sediment content, making it difficult for the drying and weighing processes. Therefore this series of work was carefully executed to obtain accurate results.

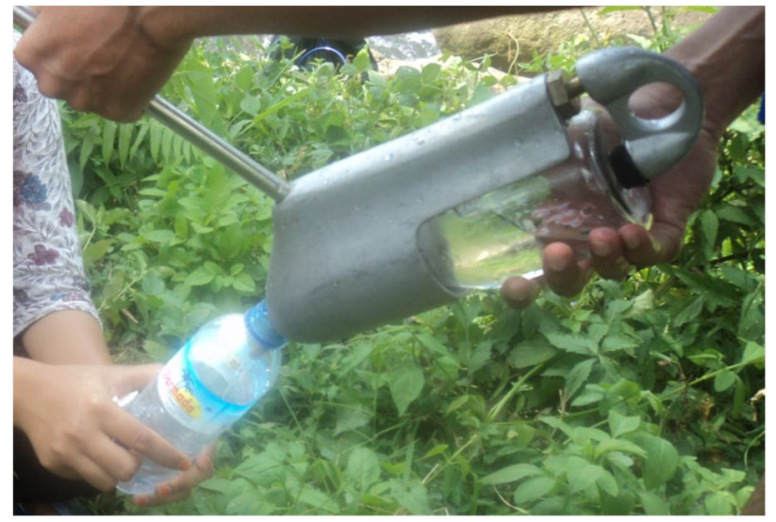

Fig. 6. Removal of sediment from US DH 48

\subsection{Suspended sediment-flow discharge rating curve}

The numerical analysis carried out resulted in an equation containing the relationship between suspended sediment concentration and river flow discharge. Field data from the measurement of suspended sediment concentration and flow discharge were converted into a series of data. Values of suspended sediment concentration were plotted versus flow discharge on a log-log grid (Fig. 7). Field data should be designed in such a way that samples were taken at various discharge conditions so that the relationship can be considered to represent sediment transport conditions that are close to the actual.

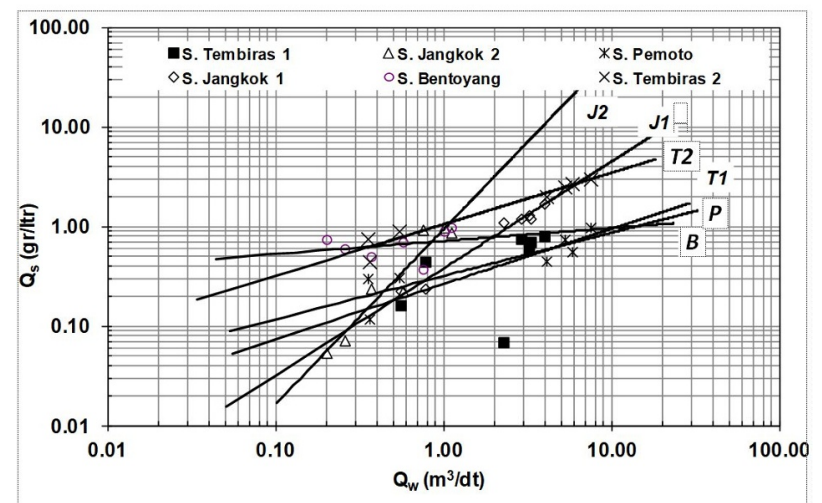

Fig. 7. Suspended sediment-flow discharge rating curve of six rivers in the upper course of Jangkok River

Sediment data measured during dry season measurement may not be adequate as the low flow was expected during this period with very limited high-flow events. A very small amount of sediment concentration may lead to an underestimated situation. On the other hand, more trapped sediment from the high-flow event during the rainy season made an overestimated calculation. Therefore, the more the data measurement taken from both seasons the more accurate the equation obtained. Measurement over a longer period than can be accommodated at present may necessitate.

Fig. 7 shows that the rating curve can be varied and has the potential to show differences in the concentration level of suspended sediment although measurement is located in adjacent sub-watersheds. It is understood that soil erosion or soil loss is not the same as sediment yield. Eroded soil may be moving and redeposited a short distance from where it was dislodged, whereas sediment yield is a portion of the eroded soil that leaves the watershed. Upon reaching the river, sediment is entrained during sporadic periods of higher flows and deposited as discharge subsides.

The rating curve can be used as a basis in estimating suspended sediment concentration and transforming it to suspended sediment transport rate at any desired discharge. As suspended sediment rate is a representation of soils loss level in the watershed the empirical relations between suspended sediment transport rate and flow discharge are beneficial to estimate watershed denudations rate and the relative stability of river courses so that the state of sediment conservation in subwatershed can be rightly expressed. Furthermore, it is hoped that the rating curve will facilitate the assessment of the overall healthy state in the watershed when coupled with other health parameters. By understanding information about the health condition of the subwatershed, anticipatory actions can be taken, especially related to disaster mitigation planning.

\subsection{Watershed map based on suspended sediment concentration}

In general, the characteristics of the sub-watersheds of Jangkok River and its tributaries have similarities, especially the average slope and vegetation cover. The difference in suspended sediment concentration shown by the suspended sediment-flow discharge rating curve is displayed on the watershed map in the form of an information box containing an equation that describes the relationship between flow discharge and suspended sediment concentration. The box also contains information on the average slope, the average flow rate, the average river width, and other related information (Fig. 8).

Determination of the river order in the upper course of the Jangkok River watershed is similar to those defined by Strahler [21]. It started from the river in a subwatershed with no tributaries. Hence, the first order (O1) is occupied by Pemoto $(\mathrm{P})$ and Bentoyang $(\mathrm{B})$ river. The highest order (O4) is the Jangkok River in the downstream part (Jd). Detailed stream order for the upper course of Jangkok River is presented in Fig. 8.

Comparison between the suspended sediment-flow discharge rating curve in Fig. 7 and the stream ordering in Fig. 8 suggests that the lower order of the river has a lower suspended sediment concentration. It is expected that smaller sub-watershed such as Bentoyang (B) and Pemoto $(\mathrm{P})$ rivers produce a smaller magnitude of sediment yield. Attention should be more focused on the 
river with a steeper line in the suspended sediment-flow discharge rating curve.

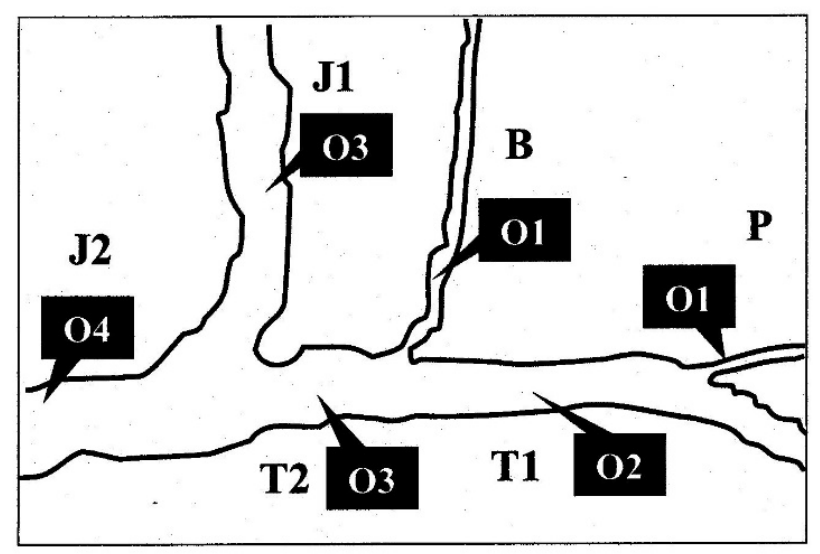

Fig. 8. Mapping of measurement locations and technical information boxes based on suspended sediment concentration

Both Jangkok upstream (J1) and Jangkok downstream (J2) experience a high increase in suspended sediment concentration as soon as flow discharge increased. Tembiras upstream (T2) has a less steep curve slope indicating a much lower increase in suspended sediment concentration. Tembiras upstream (T1) experienced a lower concentration of suspended sediment than Tembiras downstream (T2) but still higher than tributaries with the lower order, i.e. Bentoyang River (B) and Pemoto River (P).

The map in Fig. 8 is designed to provide information on watershed health assessment according to the suspended sediment concentration. Through the map, the suspended sediment rate can be estimated for any desired flow discharge in each sub-watershed. A map is a useful tool for watershed assessment whether the state of sediment rate in each sub-watershed is tolerable or intolerable magnitudes.

\section{Conclusion}

Measurement of suspended sediment concentration in the upper course of Jangkok River provides the preliminary and important source of information about the health state of the watershed and its sub-watershed. It is because the rivers are the principal route by which the products of watershed erosion are delivered downstream. Suspended sediment concentration and suspended sediment transport rate are the important source of estimates of watershed degradation and the stability of river courses.

A suspended sediment-flow discharge rating curve is very helpful in estimating the rate of suspended sediment transport in the upper course of the Jangkok River. The curve allows an estimation of the suspended sediment transport rate for each river order representing the health state of the watershed. The resulting watershed map containing information on sediment transport rates is a useful tool as guidance in planning watershed conservation management priorities. This is particularly important as the sediment transport behavior of each river is different even though they are located nearby.

This study is a preliminary step in broader studies of sedimentation behavior in the Jangkok River Network. It should be noted that the work focused on the investigation of suspended sediment concentration concerning the river flow discharge. Further investigation of land erosion in the Jangkok watershed or sub-watershed is necessitated and will greatly help in explaining the behavior of the river and its tributaries. This requires high measurement accuracy and representative sampling over a long period.

The result of this study allows the conservation authority to estimate the suspended sediment transport rate at the desired river flow. The level of suspended sediment concentration that will be listed on the map provides insight into the potential soil loss and subsequent sediment yield of the river network in the upper course of Jangkok River so that a conservation plan particularly related to disaster mitigation can be arranged accordingly. Sincere thanks are conveyed to the Water Resources Information Center (BISDA) of NTB Province for the support in providing field equipment and operator allowing this preliminary research successfully conducted.

\section{References}

1. State Gazette of the Republic of Indonesia, Government Regulation of the Republic Indonesia Number 38 the Year 2011 regarding Rivers (State Gazette of the Republic of Indonesia Year 2011 Number 74, 2011)

2. State Gazette of the Republic of Indonesia, Law Number 17 the Year 2019 regarding Water Resources (State Gazette of the Republic of Indonesia Year 2019 Number 190, 2019)

3. I. Maddock, Freshwater Biology. 41, 2 (1999)

4. P.K. Chou, B.J. Shih, C.Y. Wu, J. Chinese Inst. Eng. (2016)

5. S. Arnhold, S. Lindner, B. Lee, E. Martin, J. Kettering, T.T. Nguyen, Geoderma. s 219-220, 3 (2014)

6. S. Park, C. Oh, S. Jeon, H. Jung, C. Choi, J. Hydrology. 399, 3 (2011)

7. A. Mahmoudzadeh, W.D. Erskine, C. Myers, Australian Forestry, 65, 2 (2002)

8. A. Sharma, Geo-spatial Information Science, 13, 3 (2010)

9. H. Dandan, D. Jingcheng, G. Chaojun, M. Xingmin, G. Peng, G. Jianjian, Int. J. Sediment Res. (article in press)

10. Q. Guo, Z. Wang, Q. Zhang, Q. Zhang, N. Shen, B. $\mathrm{Wu}$, N. Tian, J. Liu, Archives Agronomy Soil Science (2020)

11. P. Borrelli, P. Panagos, M. Marker, S. Modugno, B. Schutt, Catena. 149, 3 (2016)

12. J.A. Martinez-Casasnovas, M.C. Ramos, G. Benites, Land Degr. Dev. 27, 2 (2016) 
13. Y. Saadi, H. Saidah, L.D.B. Irawan, Overview of the index and class of erosion hazard in Tanggek River Basin, in Proceeding of the $4^{\text {th }}$ National Conference on Civil Engineering, 2-3 June 2010, Sanur-Bali, Indonesia (2010)

14. Y. Saadi, I.B.G. Putra, A. Suroso, Applied Mech. Materials. 845 (2016)

15. Y. Saadi, Equation of flow discharge-sediment curve for estimating reservoir sedimentation (a case study of three rivers of Batujai Reservoir), in Proceeding of National Conference on Sustainable Infrastructure Development, 18 October 2007, Kuta-Bali, Indonesia [2007]

16. Y. Saadi, S.J. Tait, The influence of time-varying antecedent flows on the stability of mixed grain size sediment deposits, in Proceeding of $3^{\text {rd }}$ International Symposium on Environmental Hydraulics, 5-8 December 2001, Tempe-Arizona, USA (2001)
17. National Standardization Agency, Procedure for suspended sediment sampling in the river by depth integration method based on discharge distribution, SNI 3414:2008 (BSN, Jakarta, 2008)

18. Department of the Army, Engineering, and design, Sedimentation investigations of rivers and reservoirs, Engineer Manual No. 1110-2-4000 (Department of the Army, Washington, USA, 1989)

19. L.C. van Rijn, Manual sediment transport measurements, Report S304 (Delft Hydraulics, The Netherland, 2006)

20. T.J. Akai. Applied numerical methods for engineers, (John Wiley \& Sons, New York, USA, 1994)

21. A.N. Strahler, Quantitative geomorphology of drainage basins and channel networks, in Handbook of applied hydrology, V.T. Chow (Eds.), (McGrawHill, New York-USA, 1964) 